\title{
Eye movements while reading and searching spatially transformed text: A developmental examination
}

\author{
ANNE B. SPRAGINS and LESTER A. LEFTON \\ University of South Carolina, Columbia, South Carolina 29208 \\ and \\ DENNIS F. FISHER \\ Human Engineering Laboratory, Aberdeen Proving Ground, Maryland
}

\begin{abstract}
The effects of spatial manipulation on eye movement when subjects either read or searched through paragraphs were examined. Adults, third, and fifth graders were presented with paragraphs which were typed normally or in alternating case (upper and lower). The spacing between the words was either normal, filled, or absent. The results show that approximately twice as many character spaces are processed during search as during reading. Subjects made more fixations of shorter duration during search than reading. The data indicated that the ability to vary the size of the perceptual unit develops with experience. When spatial cues were unavailable, all subjects resorted to a letter-by-letter-like processing strategy in reading but not in search. Although reading and search were found to be sensitive to the same types of spatial manipulations, discrepancies of span and speed suggest qualitative differences; comprehension demands during reading can account for these differences. The data were interpreted to provide support for the two-stage model of Hochberg (1970).
\end{abstract}

Reading can be defined as a translation of spatially presented lines and spaces into meaningful information. A number of experiments have recently been performed examining the spacial manipulations of printed text in reading and visual search. Smith (1969) and Smith, Lott, and Cronnel (1969) examined word shape changes, e.g., alternating upper and lower case, in reading and search, respectively. They found that reading speed and search efficiency were reduced significantly when word shape was changed. These data were interpreted as indicating that disruption of word identification processes was responsible for the reduction of performance. An extension of the word identification notion was offered more recently by Coltheart and Freeman (1974) in a tachistoscopic word recognition task using similar manipulations.

Levin and Jones (Note 1) and Hochberg, Levin, and Frail (Note 2) have found that the eye-voice span (difference between the words spoken and the words seen) was reduced and oral reading efficiency waś disturbed when the spaces were filled between the words in textual material. They interpreted these data as indicating that filling the spaces interrupted peripheral cue accessibility leading to a strictly foveal input of the

This research was supported in part by grants from the National Institute of Education NE-G-00-3-0017 and from the National Eye Institute 1 ROL EY 01201-01 to L. Lefton. The project presented herein was performed pursuant to grants from NIE and NEI and does not represent the policy or endorsement of these agencies. This paper may be reproduced in full or in part for any purpose of the United States Govemment. Reprint requests should be sent to Lester A. Lefton, University of South Carolina, Department of Psy chology, Columbia, South Carolina 29208. stimulus materials. Reliance upon the periphery was hypothesized to be developmentally related. According to this view, adults are reliant upon the periphery for physical featural cues, whereas children rely upon foveal input and increase their dependency on the periphery with increased reading experience. These interpretations were subsequently refined by Hochberg (1970) to include a two-stage peripheral to cognitive search guidance model.

Other studies have presented reading and search speed data for adults and children who read and searched through paragraphs with word shape and word boundaries factorially combined (Fisher, 1975; Fisher \& Lefton, Note 3 ). These data consistently showed that: (1) these manipulations slowed both reading and search, (2) the effects increased with age, (3) all subjects regardless of age were reduced to the same reading and search speed in highly perturbed situations, and (4) word shape and word boundary cues were found to be interdependent in reading but not so in search. These data were interpreted in support of the Hochberg (1970) model.

Normative data about eye movements have been available for many years (Buswell, 1922; Tinker, 1958). Tinker and Paterson (1955) found that typographical variations which produce slower reading speeds resulted in a significant increase in fixation frequency, fewer words read per fixation, and a significant increase in fixation duration. In addition, eye movement data have supported the notion of a developmental progression in oculo-motor efficiency with increased reading experience (Taylor, 1965). 
The present experiment examines developmental changes in eye movement dynamics due to typographical manipulation of word shape and word boundary. A developmental examination was undertaken to aid in determining the level at which these spatial cues become an important factor in efficient reading. Three grade levels, third, fifth, and adults, were used to examine the developmental progression in oculo-motor efficiency in the tasks of reading and search. It was hypothesized that disruption of the spatial cues may force experienced readers to resort to less efficient strategy like that used by inexperienced readers. These data have both applied and theoretical importance because information from the periphery is necessary for efficient reading and search.

\section{METHOD}

\section{Subjects}

Children from the Pine Ridge School and R. E. Davis School in Columbia, South Carolina, and students from the University of South Carolina enrolled in an introductory psychology class served as subjects. Mean chronological ages of the children were 8 years, 10 months for third graders and 9 years, 6 months for fifth graders. Hereafter these children will be referred to as children in Grade 3 and Grade 5. There were 48 subjects in each grade level. One half of the subjects at each grade level served in the reading and the other half served in the search portions of the experiment. The children were chosen at random from lists provided by the reading teachers with the criterion that the children be reading at or above grade level as assessed by standardized tests and teacher evaluation.

\section{Materials}

The stimuli were paragraphs published by the Educational Development Laboratories, Huntington, New York (No. 367002). The paragraphs were typed with an IBM Selectric typewriter (Artisan 12 type), reduced photographically, and dry mounted on $3 \times 5$ reading cards. The paragraphs were standardized within each grade level for difficulty but varied between grade levels in difficulty and length. Third grade paragraphs had approximately 55 words while the fifth grade and adult paragraphs had approximately 110 words. Four different paragraphs were used at each grade level, and the same paragraphs were used for both portions of the experiment.

The stimulus paragraphs were typed with variations of spacing and case. There were three levels of spacing and two levels of case. In the normal spacing condition, there was one typewritten letter space between each word as found in normally written text. In the filled spacing condition, spaces between words were replaced with $+s$. In the absent spacing condition, the spaces between words were eliminated altogether. In the normal case condition, upper and lower case letters appeared as normally typed. In the alternating case condition, upper and lower case letters alternated through the paragraph as shown in the following phrase, "ThE BiG BoY." The three space and two case conditions were combined factorially, yielding six.conditions which were prepared for each of the four paragraphs at each grade level.

For the search task, each of the paragraphs was divided into sequences of 10 words for the adult and fifth grade paragraphs and five words for the third grade paragraphs. Six targets were selected from the sequences excluding the first and last sequence in all paragraphs for all grades. Most of the target words were nouns and all of the targets appear only once in any paragraph. All six target word positions were tested equally often across subjects.

\section{Apparatus}

Eye movements during reading and search were monitored by an Eye-Track (Standard Model 106, Biometrics, Inc.). The paragraphs were placed on the Eye-Track easel $35.6 \mathrm{~cm}$ from the subject's eyes. Each paragraph subtended a visual angle of $19.5 \mathrm{deg}$ horizontally by $7.4 \mathrm{deg}$ or less vertically. The photocells of the Eye-Track respond to infrared light reflectivity differences between the iris and the sclera. The signals are amplified and are used to drive the pens of a two-channel strip chart recorder. The Eye-Track can record horizontally displaced eye movements within $.5 \mathrm{deg}$ accuracy.

The calibration of the Eye-Track proceeds very rapidly. The subjects are asked to sit in the chair and place their chin in the chin rest and head against the rest. The subject is then asked to fixate an " $X$ " in the middle of the easel while the centering control is aligned. Next the subject is asked to fixate an ' $L$ ' and then an ' $R$,' delimiting the left and right extremes of the textual material they will read, as the respective amplitudes of the recorder were calculated.

Both forward going saccades and regressions were counted if the fixation duration was $50 \mathrm{msec}$ or more with an interfixation distance of $.5 \mathrm{deg}$ or more.

\section{Procedure}

All subjects were tested individually in rooms at their respective schools. Following brief instructional and calibration periods, subjects received their stimuli. The first paragraph presented was always a normal case - normal space paragraph and served as practice. The remaining three paragraphs were the three space conditions in one case. Thus, any one subject saw all three spacing conditions but only one case condition. Spacing was, therefore, a within-subjects variable and case a between-subjects variable. There were 12 subjects at each grade level and task in each of the case groups, and each subject provided one observation for each of the spacing manipulations. Paragraphs and conditions were completely counterbalanced across subjects.

Those subjects participating in the reading phase of the experiment were told to read through the paragraphs silently one time and then close their eyes to signal that they had finished reading. After completing the reading of one paragraph, the subject moved out of the Eye-Track to circle the correct answers in a set of 10 yes-no questions about the paragraphs. He then returned to the Eye-Track until these requirements were met for all four paragraphs.

Those subjects participating in the search task were shown the remote control button of a timer (Electronic Research Manufacturing Clock Counter, Model 2623) and told to take it in hand. Each subject was told to look for a word in the paragraph, when the word was found to close his eyes, and to press the response button. Prior to his being shown each paragraph, the subject was told and shown the target word. The subject was instructed to start at the top of the paragraph and go left to right across the lines of print top to bottom. If the target was not found on the first pass through the paragraph the subject was instructed to go through the paragraph a second time.

\section{RESULTS}

Four performance measures were calculated from the eye movement recordings and will be described successively. For each of these measures analyses of variance were performed on the data with task (reading 
Table 1

Words Per Minute for Different Stimulus Conditions

\begin{tabular}{|c|c|c|c|c|c|c|c|c|c|c|}
\hline \multirow[b]{2}{*}{ Grade } & \multicolumn{5}{|c|}{ Normal Case } & \multicolumn{5}{|c|}{ Alternating Case } \\
\hline & $\begin{array}{l}\text { Normal } \\
\text { Spacing }\end{array}$ & $\begin{array}{c}\text { Filled } \\
\text { Spacing }\end{array}$ & $\begin{array}{l}\text { Absent } \\
\text { Spacing }\end{array}$ & Mean & SD & $\begin{array}{l}\text { Normal } \\
\text { Spacing }\end{array}$ & $\begin{array}{c}\text { Filled } \\
\text { Spacing }\end{array}$ & $\begin{array}{l}\text { Absent } \\
\text { Spacing }\end{array}$ & Mean & SD \\
\hline & \multicolumn{10}{|c|}{ Reading } \\
\hline 3 & 128 & 89 & 95 & 104 & 40 & 100 & 54 & 52 & 69 & 34 \\
\hline 5 & 148 & 90 & 74 & 104 & 45 & 155 & 80 & 90 & 108 & 67 \\
\hline Adult & 256 & 214 & 134 & 201 & 73 & 174 & 63 & 55 & 97 & 62 \\
\hline \multirow[t]{2}{*}{ Mean } & 177 & 131 & 101 & 136 & 71 & 143 & 66 & 66 & 92 & 58 \\
\hline & \multicolumn{10}{|c|}{ Search } \\
\hline 3 & 161 & 138 & 102 & 134 & 52 & 146 & 81 & 111 & 113 & 52 \\
\hline 5 & 236 & 170 & 187 & 196 & 91 & 200 & 184 & 135 & 175 & 119 \\
\hline Adult & 435 & 413 & 326 & 391 & 173 & 329 & 165 & 190 & 228 & 124 \\
\hline Mean & 277 & 240 & 203 & 240 & 160 & 225 & 144 & 145 & 171 & 113 \\
\hline
\end{tabular}

or search), grade $(3,5$, adult), and case (normal or alternating) as between-effects and spacing (normal, filled, or absent) as a within-effect.

\section{Number of Words per Minute (Speed)}

The analysis comparing reading and search on the measures of words per minute yielded a significant main effect of task $[F(1 / 132)=91.08, p<.001]$, indicating that search speed is considerably faster than reading speed. In addition, the increase of speed from reading to search was found to be greater for adults and third graders as indicated by the significant interaction of Task by Grade $[\mathrm{F}(2 / 132)=14.28, \mathrm{p}<.001]$; third graders increased their speed by $29 \%$ from reading to search, adults increased their speed by $51 \%$. The data for all main effects and interactions can be seen in Table 1. Previously collected data (Fisher, 1975; Fisher \& Lefton, Note 3 ) provided an indication that case and space are handled differentially during reading and search. For this reason, the reading and search data were analyzed separately in this measure and for all subsequent measures.

Reading. Analysis of the reading speed data showed that all main effects and interactions were significant at the .001 level or beyond. Reading speed was reduced for all ages when word shape was distorted as indicated by the significant main effect of case $[\mathrm{F}(1 / 66)=31.67]$. Likewise, eliminating word boundary cues dramatically reduced reading speed as shown by the significant main effect of spacing $[F(2 / 132)=122.1]$. In addition, word shape as a cue is dependent upon the available word boundaries as indicated by the significant interaction of Case by Spacing, $[F(2 / 132)=5.84]$. The effect of typographical manipulations changed as a function of experience as shown by the significant interactions of Grade by Case $[F(2 / 66)=15.59]$, Grade by Spacing $[F(4 / 132)=10.58]$, and Grade by Case by Spacing $[F(4 / 132)=2.99, p<.05]$. These interactions indicate that alternating case brought a substantial decrease in reading speed when word spacing cues were destroyed for the adults and third graders, but these effects do not seem very dramatic for the fifth graders.

Search. The analysis of the search speed data found all main effects to be significant at the .001 level. Search speed increased with experience with printed text as shown by the significant main effect of grade $[F(2 / 66)=39.35]$. Search speed was reduced significantly when word boundaries and word shape cues were perturbed $[F(2 / 132)=13.84]$ and $[F(1 / 66)=15.56]$ for spacing and case, respectively. In

Table 2

Number of Words Per Fixation

\begin{tabular}{|c|c|c|c|c|c|c|c|c|c|c|}
\hline \multirow[b]{2}{*}{ Grade } & \multicolumn{5}{|c|}{ Normal Case } & \multicolumn{5}{|c|}{ Alternating Case } \\
\hline & $\begin{array}{l}\text { Normal } \\
\text { Spacing }\end{array}$ & $\begin{array}{r}\text { Filled } \\
\text { Spacing }\end{array}$ & $\begin{array}{l}\text { Absent } \\
\text { Spacing }\end{array}$ & Mean & SD & $\begin{array}{l}\text { Normal } \\
\text { Spacing }\end{array}$ & $\begin{array}{c}\text { Filled } \\
\text { Spacing }\end{array}$ & $\begin{array}{c}\text { Absent } \\
\text { Spacing }\end{array}$ & Mean & SD \\
\hline & & & & & & & & & & \\
\hline 3 & .70 & .54 & .60 & .61 & .21 & .52 & .32 & .31 & .38 & .17 \\
\hline 5 & .91 & .65 & .56 & .71 & .31 & .89 & .50 & .53 & .64 & .33 \\
\hline Adult & 1.20 & 1.04 & .73 & .99 & .29 & .91 & .37 & .34 & .54 & .31 \\
\hline \multirow[t]{2}{*}{ Mean } & .94 & .74 & .63 & .77 & .31 & .77 & .40 & .40 & .52 & .30 \\
\hline & & & & & & & & & & \\
\hline 3 & .84 & .80 & .60 & .75 & .33 & .80 & .58 & .61 & .66 & .28 \\
\hline 5 & 1.31 & .92 & 1.02 & 1.08 & .53 & 1.06 & .94 & .81 & .93 & .63 \\
\hline Adult & 2.19 & 2.02 & 1.70 & 1.97 & .88 & 1.62 & .87 & 1.01 & 1.17 & .70 \\
\hline Mean & 1.45 & 1.25 & 1.11 & 1.27 & .80 & 1.16 & .80 & .81 & .92 & .60 \\
\hline
\end{tabular}


Table 3

Character Spaces Per Fixation

\begin{tabular}{|c|c|c|c|c|c|c|c|c|c|c|}
\hline \multirow[b]{2}{*}{ Grade } & \multicolumn{5}{|c|}{ Normal Case } & \multicolumn{5}{|c|}{ Alternating Case } \\
\hline & $\begin{array}{l}\text { Normal } \\
\text { Spacing }\end{array}$ & $\begin{array}{c}\text { Filled } \\
\text { Spacing }\end{array}$ & $\begin{array}{c}\text { Absent } \\
\text { Spacing }\end{array}$ & Mean & SD & $\begin{array}{l}\text { Normal } \\
\text { Spacing }\end{array}$ & $\begin{array}{c}\text { Filled } \\
\text { Spacing }\end{array}$ & $\begin{array}{c}\text { Absent } \\
\text { Spacing }\end{array}$ & Mean & SD \\
\hline & & & & & & & & & & \\
\hline 3 & 3.21 & 2.34 & 2.56 & 2.70 & .98 & 2.38 & 1.32 & 1.28 & 1.66 & 1.69 \\
\hline 5 & 3.99 & 2.44 & 2.27 & 2.90 & 1.30 & 3.63 & 1.97 & 2.25 & 2.62 & 1.36 \\
\hline Adult & 5.62 & 4.83 & 3.38 & 4.61 & 1.38 & 4.12 & 1.71 & 2.23 & 2.69 & 1.75 \\
\hline \multirow[t]{2}{*}{ Mean } & 4.27 & 3.20 & 2.74 & 3.40 & 1.49 & 3.38 & 1.67 & 1.92 & 2.32 & 1.43 \\
\hline & & & & & & & & & & \\
\hline 3 & 3.92 & 3.34 & 2.79 & 3.35 & 1.54 & 3.61 & 2.33 & 2.50 & 2.82 & 1.33 \\
\hline 5 & 5.55 & 3.94 & 4.31 & 4.60 & 2.22 & 4.45 & 3.92 & 3.36 & 3.91 & 2.51 \\
\hline Adult & 10.13 & 9.21 & 7.54 & 8.96 & 4.05 & 7.57 & 4.02 & 3.92 & 5.17 & 3.30 \\
\hline Mean & 6.53 & 5.50 & 4.88 & 5.64 & 3.68 & 5.21 & 3.42 & 3.26 & 3.96 & 2.67 \\
\hline
\end{tabular}

addition, the effect of word shape manipulations was found to be greater for adults than third and fifth graders as indicated by the significant interaction of Grade by Case $[F(2 / 66)=7.25]$.

These data provide evidence to support the previous findings of a Case by Space interaction for reading but not for search. This difference may reflect a difference in processing strategy that is task dependent.

\section{Recognition Span}

Estimates of recognition span in words per fixation or character spaces per fixation were calculated by dividing the number of words or character spaces in the paragraph by the total number of fixations made by the subject. The analyses comparing reading and search data showed significant main effects of task $[F(1 / 132)=67.51$ and 76.36$]$, and significant interactions of Task by Grade $[\mathrm{F}(2 / 132)=11.07$ and 11.7], for words and character spaces per fixation, respectively. The effect of the typographical manipulation on the developmental trends for recognition span can be found in Table 2 . In addition, the data for both of these recognition span estimates can be found in Tables 3 and 4. For both of these estimates, the reduction in the size of the span resulting from

Table 4

Efficiency Measures for Normal Case/Normal Space Paragraphs

\begin{tabular}{|c|c|c|c|c|c|}
\hline \multirow[b]{2}{*}{ Grade } & \multicolumn{2}{|c|}{$\begin{array}{c}\text { Character } \\
\text { Spaces Per } \\
\text { Fixation }\end{array}$} & \multicolumn{2}{|c|}{$\begin{array}{c}\text { Words Per } \\
\text { Fixation }\end{array}$} & \multirow{2}{*}{$\begin{array}{c}\text { Words Per } \\
\text { Fixation } \\
\text { Taylor } \\
\text { (1965) }\end{array}$} \\
\hline & Mean & SD & Mean & SD & \\
\hline & \multicolumn{5}{|c|}{ Reading } \\
\hline 3 & 3.22 & .86 & .71 & .16 & .65 \\
\hline 5 & 4.00 & 1.35 & .92 & .36 & .78 \\
\hline \multirow[t]{2}{*}{ Adult } & 5.63 & 1.14 & 1.21 & .26 & 1.11 \\
\hline & \multicolumn{5}{|c|}{ Search } \\
\hline 3 & 3.92 & 1.30 & .85 & .28 & \\
\hline 5 & 5.55 & 2.30 & 1.31 & .58 & \\
\hline Adult & 10.13 & 3.6 & 2.19 & 1.03 & \\
\hline
\end{tabular}

processing word boundary and word shape distortions was greater for the adults than third graders in both reading and search; however, the magnitude of the decrease is greater in search.

Reading. The analysis of the recognition span data for reading shows that all main effects were found to be significant beyond the .001 level; grade $[F(2 / 66)=8.3$ and 10.17]; case $[F(1 / 66)=20.02$ and 30.98]; spacing $[F(2 / 132)=109.1$ and 68.1] for words and character spaces per fixation, respectively. In addition, the data for words per fixation yielded the following significant interactions: Grade by Spacing $[F(4 / 132)=9.63$, $\mathrm{p}<.001]$; Grade by Case $[\mathrm{F}(2 / 66)=5.88, \mathrm{p}<.001]$; Case by Spacing $[F(2 / 132)=6.86, p<.001]$; and Grade by Case by Spacing $[F(4 / 132)=2.72, p<.05]$. Similarly, interactions for the data for character space per fixation also showed similar trends: Grade by Case $[F(2 / 66)=5.98, \quad p<.01] ;$ Grade by Spacing $[F(2 / 132)=3.18, \quad p<.05] ;$ Case by Spacing $[F(2 / 132)=3.71, p<.05]$; and Grade by Case by Spacing $[F(4 / 132)=3.00, p<.05]$.

These data generally indicate that recognition span increases with grade, is severely decreased when cues are highly perturbed, and that these perturbations lead to a much greater reduction for the adults than the less experienced readers.

Search. The analysis of the data for recognition span estimates during search once again showed all main effects and one interaction to be significant beyond the .01 level: Grade $[F(2 / 66)=26.04$ and 35.13$]$; case $[F(1 / 66)=12.16$ and 17.58$] ;$ and spacing $[\mathrm{F}(2 / 132)=9.74$ and 11.48$]$; and the interaction of Grade by Case $[\mathrm{F}(2 / 66)=5.33$ and 7.07] for words and character spaces per fixation, respectively. Although the main effects and the second level interaction prove significant, once again the lack of an interdependence between the physical feature manipulations failed to reflect similarities to effects found in reading. Once again, a Grade by Spacing interaction failed to reach statistical significance. 
Table 5

Duration of Fixation in Milliseconds

\begin{tabular}{|c|c|c|c|c|c|c|c|c|c|c|}
\hline \multirow[b]{2}{*}{ Grade } & \multicolumn{5}{|c|}{ Normal Case } & \multicolumn{5}{|c|}{ Alternating Case } \\
\hline & $\begin{array}{l}\text { Normal } \\
\text { Spacing }\end{array}$ & $\begin{array}{c}\text { Filled } \\
\text { Spacing }\end{array}$ & $\begin{array}{l}\text { Absent } \\
\text { Spacing }\end{array}$ & Mean & SD & $\begin{array}{l}\text { Normal } \\
\text { Spacing }\end{array}$ & $\begin{array}{c}\text { Filled } \\
\text { Spacing }\end{array}$ & $\begin{array}{l}\text { Absent } \\
\text { Spacing }\end{array}$ & Mean & SD \\
\hline & & & & & & & & & & \\
\hline 3 & 398 & 464 & 470 & 444 & 87 & 356 & 431 & 392 & 393 & 126 \\
\hline 5 & 292 & 332 & 375 & 333 & 56 & 311 & 396 & 375 & 360 & 81 \\
\hline Adult & 234 & 260 & 301 & 265 & 54 & 263 & 330 & 363 & 319 & 93 \\
\hline \multirow[t]{2}{*}{ Mean } & 308 & 352 & 382 & 347 & 99 & 310 & 386 & 377 & 357 & 105 \\
\hline & & & & & & & & & & \\
\hline 3 & 276 & 304 & 318 & 299 & 67 & 343 & 374 & 347 & 355 & 80 \\
\hline 5 & 282 & 301 & 307 & 297 & 33 & 296 & 301 & 322 & 307 & 35 \\
\hline Adult & 244 & 258 & 262 & 255 & 33 & 257 & 306 & 291 & 285 & 40 \\
\hline Mean & 267 & 288 & 296 & 284 & 44 & 299 & 327 & 320 & 315 & 62 \\
\hline
\end{tabular}

\section{Fixation Duration}

Analysis of the mean fixation durations showed a significant main effect of tasks $[F(1 / 132)=36.05$, $\mathrm{p}<.001]$, indicating that the pauses were shorter in the search task than in reading. A significant interaction of Task by Spacing $[F(2 / 264)=7.99, p<.01]$ indicates that in the filled and absent space conditions, fixations were longer in reading than search. In addition, a Task by Grade interaction $[F(2 / 132)=5.22, p<.05]$ shows that the third graders used shorter fixation duration in search relative to the fixation durations during reading than did the fifth graders and adults. The fixation durations of the third graders were affected by the alternating case condition differently in reading and search, as indicated by the interaction of Task by Grade by Case $[F(2 / 132)=5.87, p<.01]$. The fixation duration data by task, grade, and typographical manipulations can be found in Table 5. The means for both fifth graders and adults showed an increase of duration of fixation for alternating case in both reading and search. However, third graders showed a decreased duration in reading alternating case and increased duration in searching through alternating case relative to normal case. The reason for this difference is not immediately clear.
Reading. The analysis of the fixation duration data indicated a significant main effect of spacing $[F(2 / 132)=28.63, p<.001]$. A post hoc Duncan multiple range test indicated that the means for the filled and absent space conditions were not different from one another but both were different from the normal condition. Fixation durations generally decreased with grade as shown by the significant main effect $[F(2 / 66)=22.54, p<.001]$ with means of 419 , 347 , and $292 \mathrm{msec}$ for Grades 3, 5 and adults, respectively. Somewhat unexpectedly, neither the main effect of case nor the interaction of Case by Space proved significant. These effects have been highly significant of all previous measures for reading. Word shape did affect fixation duration differentially by grade level as shown by the significant interaction of Grade by Case $[F(2 / 66)=4.10, p<.05]$. The Duncan multiple range test showed that third and fifth graders were not significantly different in fixation duration between alternating and normal case, yet there was a difference between these conditions for adults. The adults increased fixation duration by $25 \%$ when word shape was distorted, all the fifth graders increased duration only slightly, and the third graders actually decreased fixation duration by $10 \%$.

Table 6

Percentage of Regression

\begin{tabular}{|c|c|c|c|c|c|c|c|c|c|c|}
\hline \multirow[b]{2}{*}{ Grade } & \multicolumn{5}{|c|}{ Normal Case } & \multicolumn{5}{|c|}{ Alternating Case } \\
\hline & $\begin{array}{l}\text { Normal } \\
\text { Spacing }\end{array}$ & $\begin{array}{c}\text { Filled } \\
\text { Spacing }\end{array}$ & $\begin{array}{l}\text { Absent } \\
\text { Spacing }\end{array}$ & Mean & SD & $\begin{array}{l}\text { Normal } \\
\text { Spacing }\end{array}$ & $\begin{array}{c}\text { Filled } \\
\text { Spacing }\end{array}$ & $\begin{array}{c}\text { Absent } \\
\text { Spacing }\end{array}$ & Mean & SD \\
\hline & & & & & & & & & & \\
\hline $\begin{array}{c}3 \\
5 \\
\text { Adult } \\
\text { Mean }\end{array}$ & $\begin{array}{l}31 \\
32 \\
22 \\
28\end{array}$ & $\begin{array}{l}30 \\
31 \\
20 \\
27\end{array}$ & $\begin{array}{l}29 \\
36 \\
25 \\
30\end{array}$ & $\begin{array}{l}30 \\
33 \\
22 \\
28\end{array}$ & $\begin{array}{l}7 \\
8 \\
7 \\
9\end{array}$ & $\begin{array}{l}33 \\
25 \\
27 \\
28\end{array}$ & $\begin{array}{l}32 \\
29 \\
27 \\
29\end{array}$ & $\begin{array}{l}31 \\
27 \\
27 \\
28\end{array}$ & $\begin{array}{l}32 \\
27 \\
27 \\
29\end{array}$ & $\begin{array}{l}8 \\
6 \\
8 \\
8\end{array}$ \\
\hline & & & & & & & & & & \\
\hline $\begin{array}{c}3 \\
5 \\
\text { Adult } \\
\text { Mean }\end{array}$ & $\begin{array}{l}34 \\
21 \\
21 \\
25\end{array}$ & $\begin{array}{l}37 \\
26 \\
29 \\
31\end{array}$ & $\begin{array}{l}38 \\
25 \\
27 \\
30\end{array}$ & $\begin{array}{l}38 \\
25 \\
27 \\
30\end{array}$ & $\begin{array}{r}14 \\
9 \\
15 \\
14\end{array}$ & $\begin{array}{l}32 \\
31 \\
30 \\
31\end{array}$ & $\begin{array}{l}35 \\
33 \\
29 \\
32\end{array}$ & $\begin{array}{l}32 \\
37 \\
27 \\
32\end{array}$ & $\begin{array}{l}33 \\
33 \\
29 \\
32\end{array}$ & $\begin{array}{r}9 \\
9 \\
11 \\
10\end{array}$ \\
\hline
\end{tabular}


Search. The analysis of the search data showed the three main effects to be highly significant: spacing $[F(2 / 132)=91.74, p<.001]$; grade $[F(2 / 66)=15.74$, $\mathrm{p}<.001]$; and case $[\mathrm{F}(1 / 66)=14.43, \mathrm{p}<.001]$. No interactions proved to be significant at all for the search data.

\section{Regressions}

Regressions or right-left saccades were analyzed as a percentage of the total number of fixations made. The overall analysis showed a significant Task by Grade by Case interaction $[\mathrm{F}(2 / 132)=7.56, \mathrm{p}<.01]$. These data are shown in Table 6, in which it is apparent that third graders have more regressions in search than in reading. The third graders also produced more regression in normal case than in alternating case. Adults, by contrast, showed fewer regressions, and more for alternating case than normal case conditions.

Reading. The analysis of the regression percentage data for reading gave a significant main effect of grade $[F(2 / 66)=8.3, p<.001]$, showing that third and fifth graders had similar regression percentages and were significantly different from the adults. In addition, a significant interaction of Grade by Case $[F(2 / 66)=5.26$, $\mathrm{p}<.001]$ was found, indicating that the total percentage of regression was affected by word shape distortions differently at each grade level. The fifth graders had a high percentage of regressions for normal case while the adults had a high percentage of regressions for the alternating case condition. The percentage of regression that occurred to correct errors and overshooting in the beginning of the next line was $13 \%$, $16 \%$, and $22 \%$ for Grades 3,5 , and adults, respectively.

Search. The analysis of the regression percentage data during search indicated that regression increased when word boundaries were perturbed, shown by the significant main effect of spacing $[F(2 / 66)=4.5$, $\mathrm{p}<.05]$. In addition, regressions decreased significantly by grade, $[F(2 / 66)=5.3, p<.01]$. In this case, however, the fifth graders reflected the adult attack skills more than they did the third grade. In addition, a Grade by Case interaction $[F(2 / 66)=3.99$, $p<.05]$ was significant, indicating that the fifth graders and the adults made a larger percentage of regression on the alternating case realtive to the normal case conditions than did the third graders. Corrective regressions on the first word of the line are found to be $19 \%, 23 \%$, and $23 \%$ for Grades 3, 5, and adults, respectively.

\section{DISCUSSION}

The present experiment compared developmental changes of several eye movement indices during reading and visual search through spatially perturbed text. It was shown that experienced readers examine larger units of information and pause for shorter durations during each fixation than inexperienced readers. The experience of the adults seems to enable them to switch strategies from a large unit type of processing to a nearly letter-by-letter-like processing with the disruption of spatial cues. The strategies change in order to maximize the efficiency for handling the loss of spatial cues.

The data in this experiment generally corroborate and extend previous findings (Fisher, 1975; Fisher \& Lefton, Note 3). Taken together, these data can be accounted for by a two stage process similar to the one proposed by Hochberg (1970) and Hochberg and Brooks (1970). They hypothesized a peripheral search guidance mechanism which scans the visual periphery during a given fixation for informative physical features. When critical feature information is detected, a saccadic eye movement is initiated so that subsequent foveal processing can occur on these high information areas. The higher level interrogation, cognitive search guidance, is responsible for meaning extraction and preprogramming the visual system for subsequent high information physical features. The difference in speed of processing between reading and search suggests that reading requires a greater involvement of the cognitive search process for meaning extraction, whereas search is primarily dependent upon the visual periphery.

The Hochberg model predicts that, when spatial cues are distorted, reading and search speed as well as the size of the recognition span would decrease. The data from the present experiment verify this expectancy. In destroying the availability of the cues of word boundary and word shape, the peripheral search guidance mechanism is rendered dysfunctional.

The loss of spatial cues is detrimental to both reading and search even though the spatial cues appear to be used somewhat differently in the two tasks. This difference is exemplified by the Case by Space interaction in reading that does not appear during search. One possible means of accounting for this difference is to assume that there is limited capacity processing. During reading, processing is dependent upon comprehension demands as well as physical featural input. As the spatial cues become increasingly more perturbed (e.g., spaces eliminated and type alternated), processing efficiency deteriorates. During search, however, there is very little demand for comprehension because only physical features need be detected. Search operates in an all or none fashion and is dependent upon the availability of distinct cues. In reading the loss of peripheral information leads to a letter-by-letter process. By contrast, in search the loss of peripheral information (without comprehension demands) only leads to a decreased unit size of processing; the unit itself remains at about 2.5 to 3 characters.

Hochberg (1970) hypothesized an increased developmental trend toward dependence upon word boundary and word shape cues. The present data support this notion. Adult processing efficiency is 
greatly affected by the loss of spatial cues compared to the third graders. With experience, the adult reader has become extremely dependent upon peripheral cues whereas this is not as much the case for the beginning reader.

Foveal processing as well as peripheral processing may be disturbed by alternating word shape and boundaries. Thus, the reduction of processing to $1 \frac{112}{2}$ character spaces in reading may have been caused by impairment of foveal word identification rather than by a loss of peripheral information (Coltheart \& Freeman, 1974; Smith, 1969; Smith, Lott \& Cronnel, 1969).

When McConkie and Rayner (Note 4) destroyed word boundary, leaving the foveal area in normal print, they found that reading slowed down, but they did not find a decrease in comprehension. For the present experiment, if the interference was occurring only in the fovea and not in the periphery, the number of character spaces in search should have been reduced to about the same level as in reading. The number of character spaces per fixation in search remained almost twice that of reading. Although peripheral information is used to different degrees in reading and search, it still must be favored as the focus of the interruption effects.

Coltheart and Freeman (1974) recently hypothesized that disruption of word shape interferes with word identification processes. It would then seem to follow that word shape information is processed foveally, whereas word boundary information is processed in the periphery. This dichotomy again seems quite unlikely from the data of the present experiment and from other experiments in our laboratory (see Note 3 ). In those cases where spacing was normal and word shape was altered, there was very little decrement in reading or search speeds. When these two cues were both perturbed more severe decrements in performance resulted for both reading and search. Therefore, even though foveal processing might have been disrupted with the spatial manipulations, it is quite unlikely that a strict foveal explanation can account for the data.

Marcel (1974) has examined contextual effectiveness with good and poor readers, using stimulus materials that varied in contextual constraints. He found that both adults and children used the contextual information in word identification. He argued that adults used context more effectively than children, and thus are able to expand their perceptual information extraction capabilities. These data are consistent with the results of the present study in that the perceptual span of aduits is larger than that of inexperienced readers. The size of the perceptual span is determined not only by context as Marcel has argued, but also by spatial variables such as word shape and word boundary.

The complimentary nature of graphic (the present study) and contextual cues (Marcel, 1974) contributes to an overall increase in the perceptual span of readers which is dependent upon reading experience (cf. Rayner, 1975). The role of contextual information and spatial information varies not only with experience but with an individual reader's adopted strategies. That is, early reading may be predominantly a decoding of graphic cues or information while adults are more concerned with meaning extraction. Adults, therefore, will be able to use the contextual constraints of normal prose to a greater extent than children. Degrading of spatial cues tends to obliviate this processing hierarchy in adults and to reduce them to a letter-by-letter-like reading strategy as witnessed in inexperienced readers.

In conclusion, adults in both reading and search tend to be more dependent on spatial cues than young children. All subjects are reduced to a nearly letter-by-letter processing technique when spatial cues are highly perturbed. The cues of word shape and word boundary differ in importance in reading and search and by developmental level possibly because of identification and locating demands which change with experience. Children compensate for differing task demands by taking in fewer letters and making fewer but longer fixations during reading than search. Adults, on the other hand, remain fairly constant in fixation duration and number of fixations and simply increase recognition span from reading to search.

\section{REFERENCE NOTES}

1. Levin, $H_{\text {, }}$ \& Jones, D. Filled interword spaces and eye-voice span. In H. Levin, E. J. Gibson, \& J. J. Gibson (Eds.), The analysis of reading skill. A program of basic and applied research. Ithaca, New York: Cornell University, 1968.

2. Hochberg, J., Levin, H., \& Frail, C. Studies of oral reading: VII. How inter-word spaces affect reading. Unpublished manuscript, Comell University, 1966.

3. Fisher, D. F., \& Lefton, L. A. Pexipheral information extraction: A developmental examination of reading processes. (Submitted)

4. McConkie, G., \& Rayner, $K$. The span of effective stimulus during fixations in reading. Paper presented at the meeting of the American Education Research Association, New Orleans, Louisiana, 1973.

\section{REFERENCES}

Buswell. G. Fundamental reading habits: A study of their development. Supplementary Educational Monographs, 1922. 21.

Coltheart, M., \& Freeman, R. Case alternation impairs word identification. Bulletin of the Psychonomic Society, 1974, 3 , $102-104$.

Fisher, D. F. Reading and visual search. Memory \& Cognition. 1975, 3, 197-209.

Hochberg, J. Components of literacy: Speculations and exploratory research. In $\mathrm{H}$. Levin \& J. Williams (Eds.), Basic studies on reading. New York: Basic Books, 1970. Pp. 74-89.

Hochburs, J., \& Brooks, V. Reading as an intentional behavior. In H. Singer \& R. Ruddell (Eds.), Theoretical models and processes of reading. Newark, Del.: International Reading Association, 1970. Pp. 304-314.

Marcel, T. The effective visual field and the use of context in fast and slow readers of two ages. British Journal of Psychology, $1974,65,479-492$.

Rayner, $K$. The perceptual span and peripheral cues in reading Cognitive Psy chology, 1975, 7, 65-81.

Smith, F. Familiarity of configuration vs. discriminability of features in the visual identification of words. Psychonomic Science, 1969, 14, 261-262.

Smith, F., Lott, D. Cronnell, B. The effect of type size and case alternation on word identification. American Journal of Psy chology, 1969, 82, 248-253.

Taylor, S. E. Eye movements in reading: Facts and fallacies. American Educational Research Journal, 1965, 2, 187-202.

Tinker, M. A. Recent studies of eye movement in reading Psy chological Bulletin, 1958, 55, 215-231.

Tinkex, M. A., \& Paterson, D. G. The effect of typographical variations upon eye movement in reading. Journal of Educational Research, 1955, 49, 171-284.

(Received for publication November 2, 1974. Revision received March 31, 1975.) 